\title{
Efficacy of pamidronate in pediatric osteosarcoma patients with low bone mineral density
}

\author{
Se Won Lim, MD', \\ Ju Hyun Ahn, MD', \\ Aery Choi, MD', \\ Wan Hyeong Cho, $\mathrm{MD}^{2}$, \\ Jun Ah Lee, MD', \\ Dong Ho Kim, MD', \\ Ju-Hee Seo, MD', \\ Jung Sub Lim, MD, PhD'
}

Departments of 'Pediatrics and ${ }^{2}$ Orthopedic Surgery, Korea Cancer Center Hospital, Seoul, Korea
Purpose: Most surviving pediatric osteosarcoma patients experience osteoporosis, bone pain, and pathologic fracture during and after therapy. The aim of this study was to evaluate the efficacy and side effects of pamidronate therapy in these patients.

Methods: Nine osteosarcoma patients ( $12.8 \pm 1.6$ years of age; 5 boys and 4 girls) who had a history of nontraumatic fracture or severe pain after completing chemotherapy were included. Intravenous pamidronate $(1.5 \mathrm{mg} / \mathrm{kg})$ was given every 6 weeks for 4 to 6 cycles. Bone mineral density (BMD) of the lumbar spine was measured by dual-energy $\mathrm{x}$-ray absorptiometry. Clinical outcomes including acute side effects were also evaluated.

Results: After pamidronate treatments, all patients experienced decreased pain. Seven of 9 patients could walk without a crutch. The BMD of lumbar spine was increased by $0.108 \pm 0.062 \mathrm{mg} / \mathrm{cm}^{2}$ after $8.4 \pm 1.0$ months $(\mathrm{n}=8, P=0.017)$ and the mean $z$-score improved from $-2.14 \pm 0.94$ to $-1.76 \pm 0.95(P=0.161)$. Six patients $(67 \%)$ had an acute-phase reaction, and 2 patients had symptomatic hypocalcemia.

Conclusion: Pamidronate appears to be safe and effective for the treatment of osteosarcoma in children with low BMD and bone pain.

Keywords: Child, Osteosarcoma, Pamidronate, Bone mineral density

\section{Introduction}

Osteosarcoma is the most common primary malignant bone tumor in children and adolescents. The introduction of preoperative neoadjuvant chemotherapy has improved the survival and limb-salvage rate in osteosarcoma patients by decreasing the tumor burden before surgery ${ }^{1)}$. However, a high prevalence of osteoporosis and a high fracture rate were reported in long-term surviving osteosarcoma patients, especially in the affected limbs ${ }^{2,3)}$. Furthermore, most of the patients' bone mineral density (BMD) decreased during treatment including tumor resection and chemotherapy ${ }^{4)}$. Decreased physical activity along with poor nutrition during treatment might impair bone mass gain ${ }^{2,3)}$. Furthermore, chemotherapy agents such as methotrexate (MTX) are associated with bone pain, osteoporosis, and nontraumatic fractures ${ }^{5}$.

The bisphosphonates such as pamidronate (3-amino-1-hydroxypropylidene-bisphosphonate) have been shown to decrease the risk of skeletal fractures and bone pain in adults with metastatic breast cancer and multiple myeloma ${ }^{6,7)}$. Pamidronate is also used as a successful treatment for osteoporosis caused by osteogenesis imperfecta, quadriplegic cerebral palsy, congenital neutropenia, and leukemia without any drug-related complications in children ${ }^{8,9)}$. Furthermore, pamidronate is known to be a potent inhibitor of human osteosarcoma cell growth in vitro ${ }^{10)}$. Recently, another bisphosphonate, zoledronate, was shown to be effective in regression of osteosarcoma and repression of lung metastases in vivo ${ }^{11)}$.

The aim of this study was to evaluate the efficacy and safety of pamidronate in children with osteosarcoma who had low BMD or fracture after chemotherapy.
Received: 12 October, 2015 Revised: 15 December, 2015 Accepted: 5 January, 2016

Address for correspondence: Jung Sub Lim, MD, PhD Department of Pediatrics, Korea Cancer Center Hospital, 75 Nowon-ro, Nowon-gu, Seoul 01812, Korea

Tel: +82-2-970-1224

Fax: +82-2-970-2427

E-mail: limjs@kcch.re.kr 


\section{Materials and methods}

\section{Patients}

This study was a retrospective chart review of 9 osteosarcoma patients who were treated with pamidronate from March 2003 to March 2006 at the Korea Cancer Center Hospital. Pamidronate was administered to osteosarcoma patients with severe bone pain requiring continuous pain control including narcotics or a pathologic fracture.

\section{Dual-energy $\mathrm{x}$-ray absorptiometry measurements}

We initially evaluated their lumbar spine and both ankles through simple radiographs and then confirmed by dual energy $\mathrm{x}$-ray absorptiometry (DXA). Low BMD, a surrogate marker of osteoporosis in pediatrics, was defined by $z$-scores below -2.0 based on Korean pediatric reference data ${ }^{12)}$. The BMDs of the lumbar spine $\left(\mathrm{BMD}_{\mathrm{LS}}\right)$ were measured before and after pamidronate treatment using a Lunar Prodigy Advance DXA bone densitometer (GE Lunar Corp., Madison, WI, USA) with pediatric software (enCore 2005 ver. 9.15.010; GE Lunar Corp.).

\section{Pamidronate treatment}

Pamidronate was administered after obtaining written informed consent. Pamidronate was administered daily for 3 consecutive days, and this 3-day dosing session was repeated at 6-week intervals for at least 6 months (total of 4-6 dosing sessions). For each treatment session, $0.5-\mathrm{mg}$ pamidronate $/ \mathrm{kg}$ with $400 \mathrm{~mL}$ of $0.9 \%$ saline was infused intravenously for over 4 hours. To ensure uniformly adequate calcium and vitamin D intake, all participants were taking Cal-D-Vita 1,500 mg; Roche (elemental calcium $600 \mathrm{mg}$ and $400 \mathrm{IU}$ vitamin D) daily.

For safety, we checked for signs of hypocalcemia or other acute adverse effects of bisphosphonate at each hospital visit, and had all the patients and their parents to acknowledge the signs and symptoms. A blood sample was obtained at the start of each 3-day dosing session. After the first dose of pamidronate, ionized calcium was measured. Additional samples were obtained at the end of each 3-day session before discharge. Routinely, total calcium, phosphate, alkaline phosphatase, blood urea nitrogen, creatinine, electrolyte, magnesium, and parathyroid hormone (PTH) levels were checked by our hospital laboratory. When patients complained of hypocalcemic symptoms, additional ionized calcium, PTH, and magnesium were measured.

\section{Statistical analysis}

The data are presented as means \pm standard deviations. The net $\mathrm{BMD}_{\mathrm{LS}}$ or $\mathrm{BMD}_{\mathrm{LS}} z$-scores between before and after pamidronate therapy were assessed using a Wilcoxon signed rank test. $P$ values $<0.05$ were considered statistically significant. Analyses were carried out using SPSS ver. 13.0 (SPSS Inc., Chicago, IL, USA).

\section{Results}

\section{Patient characteristics}

The baseline characteristics of the subjects are summarized in Table 1. There were 5 boys and 4 girls with an average age of $12.8 \pm 1.6$ years (range, 10.2-15.2 years). The mean duration of the off-therapy interval before pamidronate therapy was 9.5 months (range 1-36 months). Seven patients underwent 4 dosing sessions, and 2 underwent 6 sessions. All patients had stage IIB osteosarcoma according to the American Joint Committee on Cancer staging. The primary sarcomas were at knee joint region (distal femur, 5; proximal tibia, 2; proximal fibula, 2). All patients were unable to walk owing to the bone pain, and 5 patients had previous fractures.

\section{Clinical outcome}

A marked reduction in bone pain was noted 2 to 6 weeks after the first pamidronate session, with only an occasional recurrence of mild pain before the next session. After completion of the pamidronate sessions within 6 months, 7 patients could walk without a crutch and no longer needed painkillers.

Table 1. Characteristics of the patients with osteosarcoma

\begin{tabular}{|c|c|c|c|c|c|c|c|c|}
\hline Patient & Sex & Age (yr) & Tanner stage & AJCC staging & Location & No. of previous fractures & $\mathrm{BMD}_{\mathrm{LS}}$ Z-score ${ }^{\mathrm{a})}$ & Other \\
\hline 1 & $M$ & 13.0 & III & $\| B$ & Femur, distal & 0 & -1.35 & \\
\hline 2 & $M$ & 14.8 & III & $\| B$ & Tibia, prox & 1 & -3.21 & Could not walk for 3 years \\
\hline 3 & $M$ & 15.2 & V & $\| B$ & Femur, distal & 1 & -1.45 & \\
\hline 4 & F & 11.3 & III & $\| B$ & Femur, distal & 1 & -3.89 & Local recurrence \\
\hline 5 & $F$ & 11.8 & $\|$ & $\| B$ & Fibula, prox & 0 & -1.90 & \\
\hline 6 & $\mathrm{~F}$ & 10.2 & I & $\| \mathrm{B}$ & Femur, distal & 0 & -2.28 & Wound infection \\
\hline 7 & M & 12.3 & $\|$ & $\| B$ & Femur, distal & 0 & -1.72 & \\
\hline 8 & $F$ & 13.7 & V & $\| B$ & Fibula, prox & 1 & -1.31 & Foot drop \\
\hline 9 & M & 13.8 & III & $\| B$ & Tibia, prox & 2 & -2.42 & \\
\hline
\end{tabular}


One patient (case 6) could not walk owing to a local infection, and another patient (case 4) had severe osteoporosis as she had chemotherapy for 3 years owing to local recurrence. Two patients (cases 3 and 4) had nontraumatic fractures (case 3, left femur; case 4, right femur) after cessation of the pamidronate therapy. Fracture healing was not delayed, and there was no instance of fracture nonunion.

\section{Changes in BMD}

The interval between BMD evaluations was $8.4 \pm 1.0$ months in 8 patients ( 24 months in case 1 ). Initially, the $\mathrm{BMD}_{\mathrm{LS}} z$-scores were $-2.14 \pm 0.94$ (range, -1.31 to -3.21 ). After treatment, the mean $\mathrm{BMD}_{\mathrm{LS}}$ increased by $0.108 \pm 0.062 \mathrm{mg} / \mathrm{cm}^{2}(P=0.017)$, and the mean $z$-score improved from $-2.14 \pm 0.94$ to $-1.76 \pm 0.95$ $(P=0.161)$ (Fig. 1). The $\mathrm{BMD}_{\mathrm{LS}} z$-scores of case 9 improved from and -2.42 to -0.77 by 24 months $\left(\mathrm{BMD}_{\mathrm{LS}}\right.$ increased from 0.717 to $\left.1.001 \mathrm{mg} / \mathrm{cm}^{2}\right)$. Further, the $\mathrm{BMD}_{\mathrm{LS}} z$-score of case 1 improved from -1.35 to $0.88\left(\mathrm{BMD}_{\mathrm{LS}}\right.$ increased from 0.69 to 0.87 $\left.\mathrm{mg} / \mathrm{cm}^{2}\right)$.

\section{Side effects and complications}

Six of 9 patients had an elevated body temperature over $38.5^{\circ} \mathrm{C}$ (axillary). They also complained of bone pain in the back and limbs during the first 3-day-dosing session. However, no recurrent symptoms occurred in subsequent sessions. Two patients had symptomatic hypocalcemia (cases 2 and 4). During the first session, 2 patients had perioral numbness with decreased ionized calcium, low magnesium, and increased PTH levels, which resolved with additional oral calcium and magnesium supplementation. Before each subsequent session and after the last session, the calcium and phosphate levels of all patients were within the normal range.

\section{Discussion}

This is the first report of BMD changes in pediatric osteosarcoma patients with pamidronate therapy. We found that pamidronate therapy is effective and safe for increasing BMD and controlling bone pain.

In long-term survivors of childhood limb sarcoma such as osteosarcoma or Ewing's sarcoma, the prevalence of osteopenia or osteoporosis was reported as $28.3 \%$ to $65.0 \%{ }^{2,13,14)}$. We also reported that $47.5 \%$ of long-term survivors of osteosarcoma had osteoporosis and $30.0 \%$ had osteopenia at the age of 22.0 \pm 5.1 years $^{3)}$. Furthermore, most of the patients' BMD decreased during treatment ${ }^{4)}$. One cause of osteopenia or osteoporosis is the toxicity of MTX in adjuvant chemotherapy. In particular, high-dose MTX is known to cause osteopathy with bone pain, osteoporosis, and increased risk of fracture ${ }^{15)}$. Another cause might be impaired acquisition of appropriate peak bone mass (PBM) in children with limb sarcoma. During puberty, bone mass accumulates rapidly to reach PBM through adequate exercise and nutritional support ${ }^{16)}$. However, most children with osteosarcoma are diagnosed during early to midadolescence ${ }^{1)}$. Thus, they fail to reach PBM. Subjects who fail to achieve optimal PBM and strength during childhood and adolescence are more likely to develop osteoporosis later in life $\mathrm{e}^{17)}$.

The use of bisphosphonate therapy in pediatric patients was first suggested in 1998. Cyclic administration of intravenous pamidronate in children with osteogenesis imperfecta resulted in reduced bone resorption, increased BMD, relief of bone pain, and reduced fracture incidence ${ }^{18)}$. Furthermore, efficacy of bisphosphonate treatment was proven in other pediatric diseases including juvenile idiopathic osteoporosis, steroidinduced osteoporosis, quadriplegic cerebral palsy, and juvenile rheumatoid arthritis ${ }^{19-21)}$. Our study also supports the effect of pamidronate in increasing BMD and relief of bone pain in osteosarcoma patients with osteoporosis, although a reduction in fracture incidence could not be ascertained owing to the limited number of cases. Most patients in this study did not use analgesics and could walk with weight bearing in the affected limb after the pamidronate treatment. In acute lymphoblastic leukemia patients with steroid-associated osteonecrosis, pamidronate appeared to be effective in reducing bone pain ${ }^{22)}$. Recently, Meyers et al. ${ }^{23)}$ reported pamidronate improved the durability of limb reconstruction without impairing the efficacy of chemotherapy in osteosarcoma patients.

In this study, $67 \%$ of patients had an acute-phase reaction (influenza-like symptoms), and 22\% had symptomatic hypocal-
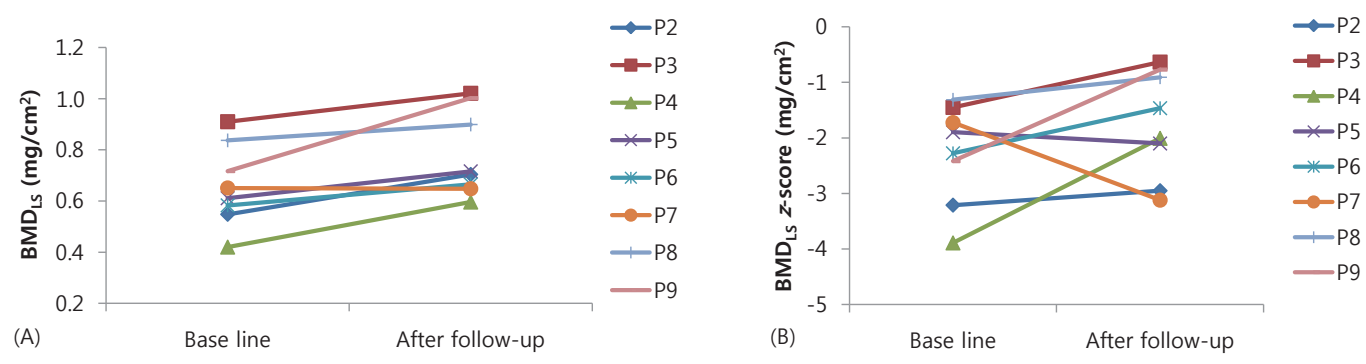

Fig. 1. The lumbar spine bone mineral density changes after pamidronate treatment. (A) Changes in bone mineral density lumbar spine $\left(B M D_{L S} \mathrm{mg} / \mathrm{cm}^{2}\right.$ ) of osteosarcoma patients ( $\mathrm{P} 2$ to $\mathrm{P} 9$, case 2 to 9 ) at baseline and after follow-up. (B) Changes in the $\mathrm{BMD}_{\mathrm{LS}} \mathrm{z}$-scores of osteosarcoma patients. The interval from first $\mathrm{BMD}_{L S}$ evaluation to next $\mathrm{BMD}_{\mathrm{LS}}$ evaluation was $8.4 \pm 1.0$ months. 
cemia. This result is compatible with other bisphosphonate studies of pediatric patients ${ }^{18,24-27}$. An acute-phase reaction including fever, malaise, nausea, diarrhea, and muscle or bone pain occurs in most children with the initiation of intravenous or oral agents. These symptoms began typically within 1-3 days of initial exposure, lasted only a few days, and rarely recurred with subsequent doses. Abnormal laboratory findings including hypocalcemia and hypophosphatemia, which were less common and typically had no symptoms, resolved within several days ${ }^{27)}$. Our patients with hypocalcemia also had hypomagnesemia. We assume the other chemotherapy regimen, cisplatin, induces hypomagnesemia through its renal toxicity ${ }^{28)}$. Magnesium deficiency is known to contribute to hypocalcemia ${ }^{29}$. Thus, a correction of magnesium deficiency before pamidronate therapy is essential along with adequate vitamin D and calcium intake in osteosarcoma patients. Until now, the 3-year safety and efficacy data of bisphosphonate use in children for secondary osteoporosis were considered sufficient in a 2007 Cochrane review $^{30)}$.

We acknowledge some limitations in our study. First, selection bias may exist because of the retrospective chart review of only 9 osteosarcoma patients. Second, the small number of patients without controls precludes a definite conclusion regarding the effectiveness of pamidronate on BMD. Finally, the changes in femur neck BMD might be more related to walking ability. However, we could not measure femur neck BMD serially for safety and technical reasons.

In conclusion, we found that pamidronate therapy is safe and effective in increasing BMD and controlling bone pain in children and adolescents with osteosarcoma and low BMD with or without fracture. However, the small number of cases precludes a definitive conclusion on whether pamidronate therapy is effective in preventing fracture. Further longitudinal studies with larger samples are needed.

\section{Conflict of interest}

No potential conflict of interest relevant to this article was reported.

\section{References}

1. Ottaviani G, Jaffe N. The epidemiology of osteosarcoma. Cancer Treat Res 2009;152:3-13.

2. Holzer G, Krepler P, Koschat MA, Grampp S, Dominkus M, Kotz R. Bone mineral density in long-term survivors of highly malignant osteosarcoma. J Bone Joint Surg Br 2003;85:231-7.

3. Lim JS, Kim DH, Lee JA, Kim DH, Cho J, Cho WH, et al. Young age at diagnosis, male sex, and decreased lean mass are risk factors of osteoporosis in long-term survivors of osteosarcoma. J Pediatr Hematol Oncol 2013;35:54-60.

4. Ahn JH, Cho WH, Lee JA, Kim DH, Seo JH, Lim JS. Bone mineral density change during adjuvant chemotherapy in pediatric osteosarcoma. Ann Pediatr Endocrinol Metab 2015;20:150-4.

5. Pirker-Fruhauf UM, Friesenbichler J, Urban EC, ObermayerPietsch B, Leithner A. Osteoporosis in children and young adults: a late effect after chemotherapy for bone sarcoma. Clin Orthop Relat Res 2012;470:2874-85.

6. Hortobagyi GN, Theriault RL, Lipton A, Porter L, Blayney D, Sinoff C, et al. Long-term prevention of skeletal complications of metastatic breast cancer with pamidronate. Protocol 19 Aredia Breast Cancer Study Group. J Clin Oncol 1998;16:2038-44.

7. Terpos E, Berenson J, Cook RJ, Lipton A, Coleman RE. Prognostic variables for survival and skeletal complications in patients with multiple myeloma osteolytic bone disease. Leukemia 2010;24:1043-9.

8. Srivastava T, Alon US. The role of bisphosphonates in diseases of childhood. Eur J Pediatr 2003;162:735-51.

9. Sebestyen JF, Srivastava T, Alon US. Bisphosphonates use in children. Clin Pediatr (Phila) 2012;51:1011-24.

10. Sonnemann J, Eckervogt V, Truckenbrod B, Boos J, Winkelmann W, van Valen F. The bisphosphonate pamidronate is a potent inhibitor of human osteosarcoma cell growth in vitro. Anticancer Drugs 2001;12:459-65.

11. Ory B, Heymann MF, Kamijo A, Gouin F, Heymann D, Redini F. Zoledronic acid suppresses lung metastases and prolongs overall survival of osteosarcoma-bearing mice. Cancer 2005; 104:2522-9.

12. Lim JS, Hwang JS, Lee JA, Kim DH, Park KD, Cheon GJ, et al. Bone mineral density according to age, bone age, and pubertal stages in korean children and adolescents. J Clin Densitom 2010;13:68-76.

13. Ruza E, Sierrasesúmaga L, Azcona C, Patino-Garcia A. Bone mineral density and bone metabolism in children treated for bone sarcomas. Pediatr Res 2006;59:866-71.

14. Müller C, Winter CC, Rosenbaum D, Boos J, Gosheger G, Hardes J, et al. Early decrements in bone density after completion of neoadjuvant chemotherapy in pediatric bone sarcoma patients. BMC Musculoskelet Disord 2010;11:287.

15. Stanisavljevic S, Babcock AL. Fractures in children treated with methotrexate for leukemia. Clin Orthop Relat Res 1977;(125):139-44.

16. Bonjour JP, Chevalley T. Pubertal timing, bone acquisition, and risk of fracture throughout life. Endocr Rev 2014;35:820-47.

17. Cooper C, Westlake S, Harvey N, Javaid K, Dennison E, Hanson M. Review: developmental origins of osteoporotic fracture. Osteoporos Int 2006;17:337-47.

18. Glorieux FH, Bishop NJ, Plotkin H, Chabot G, Lanoue G, Travers R. Cyclic administration of pamidronate in children with severe osteogenesis imperfecta. N Engl J Med 1998;339:947-52.

19. Shaw NJ, Boivin CM, Crabtree NJ. Intravenous pamidronate in juvenile osteoporosis. Arch Dis Child 2000;83:143-5.

20. Henderson RC, Lark RK, Kecskemethy HH, Miller F, Harcke HT, Bachrach SJ. Bisphosphonates to treat 
osteopenia in children with quadriplegic cerebral palsy: a randomized, placebo-controlled clinical trial. J Pediatr 2002;141:644-51.

21. Cimaz R, Gattorno M, Sormani MP, Falcini F, Zulian F, Lepore L, et al. Changes in markers of bone turnover and inflammatory variables during alendronate therapy in pediatric patients with rheumatic diseases. J Rheumatol 2002;29:1786-92.

22. Nguyen T, Zacharin MR. Pamidronate treatment of steroid associated osteonecrosis in young patients treated for acute lymphoblastic leukaemia--two-year outcomes. J Pediatr Endocrinol Metab 2006;19:161-7.

23. Meyers PA, Healey JH, Chou AJ, Wexler LH, Merola PR, Morris CD, et al. Addition of pamidronate to chemotherapy for the treatment of osteosarcoma. Cancer 2011;117:173644.

24. Batch JA, Couper JJ, Rodda C, Cowell CT, Zacharin M. Use of bisphosphonate therapy for osteoporosis in childhood and adolescence. J Paediatr Child Health 2003;39:88-92.

25. Gandrud LM, Cheung JC, Daniels MW, Bachrach LK
Low-dose intravenous pamidronate reduces fractures in childhood osteoporosis. J Pediatr Endocrinol Metab 2003; 16:887-92.

26. Lee J, Yoon J, Lee YA, Lim JS, Shin CH, Yang SW. Pamidronate therapy in children and adolescents with secondary osteoporosis. J Korean Soc Pediatr Endocrinol 2011;16:17884.

27. Bachrach LK, Ward LM. Clinical review 1: Bisphosphonate use in childhood osteoporosis. J Clin Endocrinol Metab 2009;94:400-9.

28. Lajer H, Daugaard G. Cisplatin and hypomagnesemia. Cancer Treat Rev 1999;25:47-58.

29. Reddy CR, Coburn JW, Hartenbower DL, Friedler RM, Brickman AS, Massry SG, et al. Studies on mechanisms of hypocalcemia of magnesium depletion. J Clin Invest 1973;52:3000-10.

30. Ward L, Tricco AC, Phuong P, Cranney A, Barrowman $\mathrm{N}$, Gaboury I, et al. Bisphosphonate therapy for children and adolescents with secondary osteoporosis. Cochrane Database Syst Rev 2007;(4):CD005324. 